R.L. Oliveira Pinto, F. Maloberti: "X ray and blue print: tools for mosfet analog circuit design addressing short-channel effects"; Proc. of the 2004 International Symposium on Circuits and Systems, ISCAS 2004, Vol. 5, 23-26 May 2004, pp. 277-280.

(C)20xx IEEE. Personal use of this material is permitted. However, permission to reprint/republish this material for advertising or promotional purposes or for creating new collective works for resale or redistribution to servers or lists, or to reuse any copyrighted component of this work in other works must be obtained from the IEEE. 


\title{
$X$ RAY AND BLUE PRINT: TOOLS FOR MOSFET ANALOG CIRCUIT DESIGN ADDRESSING SHORT-CHANNEL EFFECTS
}

\author{
R. L. Oliveira Pinto ${ }^{I}, F$. Maloberti ${ }^{2}$ \\ ${ }^{1}$ Texas A \& M University, USA \\ ${ }^{2}$ The University of Texas at Dallas, USA \\ rodrigo@ee.tamu.edu
}

\begin{abstract}
An automatic engine built in the Java language designs transistors in few and easy steps. The results come from a combination of parameter extraction and simple analytical models that address the short-channel effects by referring them to the Early voltage. The outcome is precise output conductance, thermal noise coefficient and thermal noise from a friendly graphical user interface. Design and simulations of common-source amplifiers show the efficiency of the automation.
\end{abstract}

\section{INTRODUCTION}

Automation of analog circuits has been a hot topic for the past few years $[1,2]$, yet the analog designers still rely basically on circuit simulators and layout editors to accomplish their goals. There are solutions for complete sizing of MOSFET circuits, however, requiring manual modeling for further automation [3]. Circuit level design tools hide their methods from the analog designers who prefer to use their own design procedures [1]. Here we propose automation at transistor level by providing access to precise values of the main parameters of an amplifier to be used at the circuit level design.

Two design tools implemented in Java aid the designer to size MOSFET's for analog circuits. The first tool, which is called X Ray, extracts amplifier parameters mainly based on the inversion level $[4,5,6,7]$. The second tool, which is called Blue Print, combines the data points from X Ray and analytical expressions [8] to size the transistors.

This paper describes the tools and the basis of the automation [8] as well as presents designs and simulation results to validate the method.

\section{X RAY}

$\mathrm{X}$ Ray is a program that extracts the Early voltage VA, thermal noise coefficient $\gamma$, and thermal noise $i_{d}{ }^{2}$ based on a given range of inversion level $\mathrm{i}_{\mathrm{f}}$, drain-to-source-voltage $\mathrm{V}_{\mathrm{DS}}$ and channel length $\mathrm{L}$, for a specific technology, temperature $\mathrm{T}$ and channel

R. L. Oliveira Pinto is sponsored by CAPES, research agency of the Brazilian Ministries of Science and Technology and Education. type $(\mathrm{N}$ or $\mathrm{P})$. The correct values of Early voltage are fundamental to design DC gain. Also, good prediction of the thermal noise is important to properly reduce its value in any amplifier design.

The main parameter extracted is the Early voltage for each point of each drain current because it reflects all the short channel effects modeled in the mobility and channel length [8], as equations (1) to (3) demonstrate. Equation (1) is the drain current $I_{D}$ for hand design purposes. It is function of the gate-tosource voltage $\mathrm{V}_{\mathrm{GS}}$ and drain-to-source voltage $\mathrm{V}_{\mathrm{DS}}$ working with a constant Early voltage. $V_{D S s a t}$ is $V_{D S}$ in the saturation point. $\mu$ is the mobility, $\mathrm{C}^{\prime}{ }_{\text {ox }}$ is the oxide capacitance per unit area, and $\mathrm{V}_{\mathrm{T}}$ is the threshold voltage. The geometry is given by the channel width W and length L. Equation (2) is a simplified model of $I_{D}$ for simulation purposes where $\mu$ and $L$ are replaced by $\mu_{\mathrm{EFF}}$ and $\mathrm{L}_{\mathrm{EFF}}$, respectively effective mobility and length, both containing short-channel effects. From (1) and (2) it is straightforward to find (3) and see that it is possible to refer the short-channel effects of $\mu_{\mathrm{EFF}}$ and $\mathrm{L}_{\mathrm{EFF}}$ to VA.

$$
\begin{gathered}
I_{D}=\frac{\mu C_{O X}^{\prime}}{2} \frac{W}{L}\left(V_{G S}-V_{T}\right)^{2}\left(\frac{V_{D S}-V A}{V_{D S s a t}-V A}\right) \\
I_{D}=\left(\frac{\mu_{E F F}}{L_{E F F}}\right) \frac{C_{O X}^{\prime}}{2} W\left(V_{G S}-V_{T}\right)^{2} \\
\frac{\mu_{e f f}}{L_{e f f}}=\frac{\mu}{L}\left(\frac{V_{D S}-V A}{V_{D S s a t}-V A}\right)
\end{gathered}
$$

The designer can work directly with points of VA during the hand design instead of complicated models of $\mu_{\mathrm{EFF}}$ and $\mathrm{L}_{\mathrm{EFF}}$, however, the problem now is how to determine the space of extraction of VA that is applicable to as many designs as possible. The Early voltage depends on $\mathrm{i}_{\mathrm{f}}, \mathrm{V}_{\mathrm{DS}}, \mathrm{L}$ and $\mathrm{T}$ [9]. The inversion level and drain-to-source voltage have practical physical limits that naturally establish a space of extraction: if between 1 and 1000, which means from weak to strong inversion, and $\mathrm{V}_{\mathrm{DS}}$ between $0 \mathrm{~V}$ and the maximum voltage supply. We can normalize the channel length by the minimum length $\mathrm{L}_{\mathrm{MIN}}$ and define a maximum normalized length for a particular design, for instance $\mathrm{L} / \mathrm{L}_{\mathrm{MIN}}$ equals to 9 . The temperature is kept fixed. Once the points of VA are extracted they can be stored and used for several designs because $i_{\mathrm{f}}$ is 
independent of geometry [4], and VA is not a function of the channel width $\mathrm{W}$ [9].

For design purposes, all the transistors that have the same $i_{\mathrm{f}}$ can share the same set of curves. The geometry is adjusted according to the drain current needed by using equations (4) and (5) [4], where $I_{S}$ is the normalization current, $n$ is the slope factor, and $\phi_{\mathrm{t}}$ is the thermal voltage.

$$
i_{f}=\frac{I_{D}}{I_{S}} \quad \text { (4) } \quad I_{S}=\mu n C_{o x}^{\prime} \frac{\phi_{t}^{2}}{2} \frac{W}{L}
$$

Figure 1 presents the X Ray user interface showing its input and output areas.

The input area accepts steps of normalized channel length, as well as steps of inversion level. The minimum length for normalization has its respective field. $V_{D S}$ receives a maximum range and resolution. The button "Load Model" opens a file chooser dialog box to assign a Spice transistor model to the system. An input field receives the temperature, and a radio button selects the channel type. Because $i_{f}$ is independent of geometry, the system has a single transistor width as input.

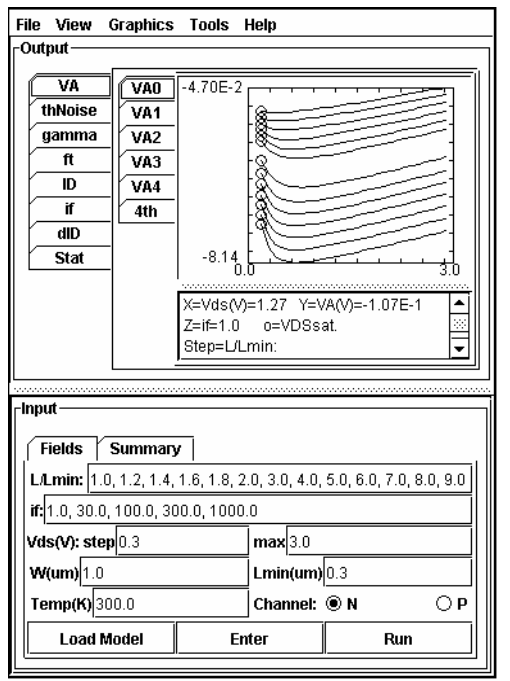

Figure 1. X Ray Graphical User Interface

An internal simulation module generates a Spice file and runs a simulator whose result is a set of drain currents for each channel length and inversion level for a given range of drain-tosource voltage. The set of VA's extracted will reflect the short channel effects of the mosfet model and simulator used. The current implementation of $\mathrm{X}$ Ray runs Spectre, however, it could be any other Spice-like simulator in any platform that has the Java virtual machine installed.

The output area presents the results in sets of curves where each set is for one $i_{f}$. Figure 1 shows VA0 that is the Early voltage for if $=1$ where $V A$ is in the $y$ axis and $V_{D S}$ is in the $x$ axis. Each curve is for one step of $\mathrm{L} / \mathrm{L}_{\mathrm{MIN}}$.

The thermal noise coefficient and thermal noise presented by X Ray follow expressions (6) and (7) [8], where $q$ is the electronic charge and $\Delta \mathrm{f}$ is the bandwidth. The short-channel effects for $\gamma$ and $i_{d}{ }^{2}$ are taken into account by assigning VA for each $i_{f}$ and $V_{D S}$ in (6) and (7). Likewise $\gamma$ and $i_{d}{ }^{2}$, the intrinsic cut-off frequency $\mathrm{f}_{\mathrm{T}}$ that accounts short-channel effects also comes from a mixture of an analytical model, equation (8) [8], and data points of VA.

$$
\begin{aligned}
& \gamma_{s a t}= \frac{1}{3}\left(2+\frac{1}{i_{f}}-\frac{\sqrt{1+i_{f}}}{i_{f}}\right)\left(\frac{V_{D S}-V A}{V_{D S s a t}-V A}\right) \\
& \frac{i_{d}^{2}}{8 q I_{S} \Delta f}=\lambda\left(\sqrt{1+i_{f}}-1\right) \\
& f_{T}=\frac{\mu \phi_{t}}{2 \pi L^{2}} 2\left(\sqrt{1+i_{f}}-1\right)\left(\frac{V_{D S}-V A}{V_{D S s a t}-V A}\right)
\end{aligned}
$$

For the hand design, the user can pick VA, $\gamma$ and $f_{\mathrm{T}}$ from the graphics for a given $i_{f}, V_{D S}$ and L [8]. Graphics for $i_{d}^{2}$ are also available, however, requiring adjustments according to the width needed. Another option is to size the transistor by means of Blue Print, as shown in the next section.

\section{BLUE PRINT}

Blue Print is an experimental calculator attached to X Ray that presents all the trade-offs involving a single transistor design by imitating the hand calculation process. Table 1 shows the expressions implemented by Blue Print, where some are analytical equations [4] while others are data points provided by $\mathrm{X}$ Ray. In both cases the variables involved are the ones required to design MOSFET amplifiers: the gate transconductance $\mathrm{g}_{\mathrm{m}}$, and the output resistance $\mathrm{r}_{\mathrm{O}}$, besides the ones already mentioned for noise, geometry, current, intrinsic cut-off frequency, and Early voltage. The analytical models used here work continuously from weak to strong inversion, hence, easy to be implemented for calculation purposes once there is no need of any interpolation function. The Blue Print graphical user interface shows only the design variables and hides the constants $\mu, \mathrm{n}, \mathrm{C}^{\prime}{ }_{\mathrm{ox}}, \phi_{\mathrm{t}}$. Figure 2 shows the interface, where each row represents a variable and each column one of the relations from Table 1 .

The numbers given by Blue Print will be tailored for the simulator, technology and transistor model used by X Ray, even though the design equations [4] are different from the model used by the simulator. This approach is based on the assumption that the long channel transistor models should have similar behavior, both the ones that use any interpolation function to fill the gap between weak and strong inversion and those that work continuously, being the Early voltage the only parameter needed to be extracted in order to address shortchannel effects for each particular model.

To design a transistor the user enters the desired value in the respective field and pushes one of the buttons in that row. If only one variable is left in that column, this variable is immediately determined. If one single variable is left in any other column as well, this one is also automatically calculated. This process continues until either more than one variable is left or all parameters are determined. One major advantage in the Blue Print is the fact that the numbers can be entered in any sequence, therefore providing to the designer freedom to choose what are the main parameters for that particular design, i.e., 
there is no preset design procedure. For instance, in the relation between $V_{D S s a t}$ and $i_{f}$, the designer can either enter first $V_{D S s a t}$ and then $i_{f}$ or vice versa, the first one entered determines the other one. The designs are stored in the draft area under the calculator. Once the design is finished the user can reset the calculator and start another design.

The system supports several instances of both X Ray and Blue Print opened simultaneously, hence, allowing on the same screen the design of many transistors of $\mathrm{N}$ and $\mathrm{P}$ channels. This is a desirable feature while designing several transistors.

Table 1. Equations implemented in the Blue Print

\begin{tabular}{|l|c|c|}
\hline Index & Expressions & Relations \\
\hline 1 & $\frac{n \phi_{t} g_{m}}{I_{D}}=\frac{2}{1+\sqrt{1+i_{f}}}$ & $\mathrm{~g}_{\mathrm{m}}, \mathrm{I}_{\mathrm{D}}, \mathrm{i}_{\mathrm{f}}$ \\
\hline 2 & $i_{f}=\frac{I_{D}}{\mu n C_{o x}^{\prime} \frac{\phi_{t}^{2}}{2} \frac{W}{L}}$ & $\mathrm{I}_{\mathrm{D}}, \mathrm{i}_{\mathrm{f}}, \mathrm{W}, \mathrm{L}$ \\
\hline 3 (data points) & $\mathrm{f}_{\mathrm{T}}=\mathrm{f}\left(\mathrm{i}_{\mathrm{f}}, \mathrm{V}_{\mathrm{DS}}, \mathrm{L}\right)$ & $\mathrm{i}_{\mathrm{f}}, \mathrm{L}, \mathrm{f}_{\mathrm{T}}, \mathrm{V}_{\mathrm{DS}}$ \\
\hline 4 & $\frac{V_{D S s a t}}{\phi_{t}}=\left(\sqrt{1+i_{f}}-1\right)+4$ & $\mathrm{i}_{\mathrm{f}}, \mathrm{V}_{\mathrm{DSsat}}$ \\
\hline 5 (data points) & $\mathrm{VA}=\mathrm{f}\left(\mathrm{i}_{\mathrm{f}}, \mathrm{V}_{\mathrm{DS}}, \mathrm{L}\right)$ & $\mathrm{i}_{\mathrm{f}}, \mathrm{L}, \mathrm{V}_{\mathrm{DS}}, \mathrm{VA}$ \\
\hline 6 & $r_{o}=\frac{V A}{I_{D}}$ & $\mathrm{I}_{\mathrm{D}}, \mathrm{VA}, \mathrm{r}_{\mathrm{O}}$ \\
\hline 7 (data points) & $\gamma=\mathrm{f}\left(\mathrm{i}_{\mathrm{f}}, \mathrm{V}_{\mathrm{DS}}, \mathrm{L}\right)$ & $\mathrm{i}_{\mathrm{f}}, \mathrm{L}, \mathrm{V}_{\mathrm{DS}}, \gamma$ \\
\hline 8 (data points) & $\mathrm{i}_{\mathrm{d}}^{2}=\mathrm{f}\left(\mathrm{i}_{\mathrm{f}}, \mathrm{V}_{\mathrm{DS}}, \mathrm{L}, \mathrm{W}\right)$ & $\mathrm{i}_{\mathrm{f}}, \mathrm{W}, \mathrm{L}, \mathrm{V}_{\mathrm{DS}}, \mathrm{i}_{\mathrm{d}}{ }^{2}$ \\
\hline
\end{tabular}

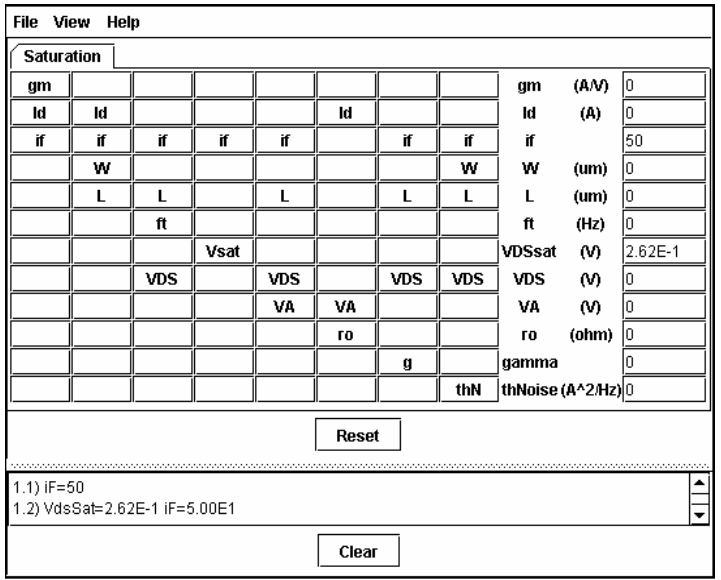

Figure 2. Blue Print Graphical User Interface

To access the data points the tool performs a simple linear interpolation between the points in the available range of values. If a certain value is out of range an error message is given. The precision, of course, will depend on the resolution of the points. This is why it is called Blue Print.

One can notice that depending on the sequence we can find more than one result for a certain parameter. It is also possible a different arrangement for the equations. For multiple results Blue Print takes the first one found. A better equation arrangement is a subject for another kind of study. The difficulties and constraints of a transistor level design, though, are clearly seen. The knowledge gained with this tool can help to create engines for circuit level design in the future.
In short, Blue Print automatically performs the hand calculation design that would require manipulation of several equations and manual reading of graphics.

\section{DESIGNS AND SIMULATION RESULTS}

This section compares results from X Ray / Blue Print with simulations using BSIM $3 \mathrm{v} 3$ of a common-source amplifier as the one seen in Figure 3. The technology used was TSMC25, $\mathrm{L}_{\mathrm{MIN}}=0.3 \mu \mathrm{m}$, run T21Q (MM_NON-EPI). We extracted the parameters for both $\mathrm{N}$ and $\mathrm{P}$ channels using if equals $1,30,100$, 300 and $1000, \mathrm{~L} / \mathrm{L}_{\mathrm{MIN}}$ equals $1,1.2,1.4,1.6, .1 .8,2,3,4,5,6$, 7,8 and $9, V_{D S}$ from 0 to $3 \mathrm{~V}$ with $0.3 \mathrm{~V}$ step, width equals $1 \mu \mathrm{m}$, the minimum technology length and temperature of $300 \mathrm{~K}$

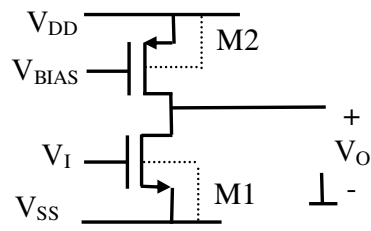

Figure 3. Common-Source (CS) Amplifier

Table 2 shows a design of a common source amplifier to compare the values given by Blue Print and the ones found in the simulations regarding the DC gain $\mathrm{A}_{\mathrm{vo}}$ of the amplifier. The Blue Print column presents the steps used for the design, actually the ones input in the calculator, and the respective results. The first transistor designed was the NMOS, with $\mathrm{i}_{\mathrm{f}}, \mathrm{W}$ and $L / L_{M I N}$ arbitrarily chosen. The $V_{D S}$, required in this method [8], is half of the voltage supply, $\mathrm{V}_{\mathrm{DD}}$ to $\mathrm{V}_{\mathrm{SS}}$, of $1.5 \mathrm{~V}$. Among several other parameters, we primarily focus on $\mathrm{g}_{\mathrm{m}}$, and VA once they are directly related to the gain, as equations (9) and (10) [8] show, and $I_{D}$ because it is needed to design the PMOS. $\mathrm{W}$ and VA are the main parameters for the $\mathrm{P}$ transistor, whose design also requires $\mathrm{V}_{\mathrm{DS}}[8]$.

$$
\begin{gathered}
A_{V O}=\frac{g_{m 1}}{g_{O 1}+g_{O 2}} \\
A_{V O}=\frac{1}{\phi_{t} n}\left(\frac{2}{\sqrt{1+i_{f 1}}+1}\right)\left(\frac{1}{1 / V A_{1}+1 / V A_{2}}\right)
\end{gathered}
$$

The design and simulations values agree fairly well. The Early voltages given by the simulations are very close to the ones provided by Blue Print, proving that the information of VA of a $1 \mu \mathrm{m}$ width transistor can be used for any width. The theoretical and simulated DC gains are, respectively, 25 and 37. Overall, the numbers quickly provided by Blue Print matched the ones found in the simulations.

Access to the short-channel effects of the thermal noise that are usually evaluated only during the simulations is desirable during the hand calculation design [8]. Table 3 compares the design and simulation of the CS amplifier for several voltage supplies. We chose this criterion due to the influence of $V_{D S}$ on $\mathrm{VA}$, and the correlation of VA with the thermal noise, as seen in equations (6) and (7) [8]. The parameters needed to calculate the noise are those given by Equation (11), which takes into 
account the short-channel effects based on data points of $i_{d}^{2}$, $\mathrm{i}_{\mathrm{d} 2}^{2}$, and $\mathrm{VA}_{1}$, this last one to model those effects in $\mathrm{g}_{\mathrm{m} 1}$ [8]. Equation (11) also keeps the $\mathrm{V}_{\mathrm{DSsa}}$, which is normally ignored while calculating the influence of VA, because it presented better results for the noise.

The design for the NMOS was based on $i_{\mathrm{f}}$ equals 300 , W of $12.525 \mu \mathrm{m}$, minimum length, and the steps of $\mathrm{V}_{\mathrm{DS}}$ presented in Table 3. The $g_{m}$ for the NMOS is $2.51 \mathrm{~mA} / \mathrm{V}$, whose $\mathrm{i}_{\mathrm{d} 11}{ }_{1}$ and $\mathrm{VA}_{1}$ are the ones seen in Table 3. The PMOS design also used $i_{f}$ of $300, I_{D}$ equals $7.76 \mu \mathrm{A}$, this one from the NMOS design, minimum length, and the same steps of $\mathrm{V}_{\mathrm{DS}}$. The final width for the PMOS was $35 \mu \mathrm{m}$ and the values for $\mathrm{i}_{\mathrm{d}}{ }^{2}$ are also found in Table 3.

Table 2. CS Amplifier Design and Simulations for $A_{v o}$

\begin{tabular}{|l|l|l|l|}
\hline \multicolumn{3}{|l|}{ Blue Print } & \multicolumn{2}{|l|}{ Simulations } \\
\hline $\mathrm{N}$ & $\mathrm{P}$ & $\mathrm{N}$ & $\mathrm{P}$ \\
\hline Steps: & Steps: & & \\
$1: \mathrm{i}_{\mathrm{f}}=30$ & $5: \mathrm{i}_{\mathrm{f}}=30$ & $\mathrm{i}_{\mathrm{f}}=32.8$ & $\mathrm{i}_{\mathrm{f}}=32.8$ \\
$2: \mathrm{W}=50 \mu \mathrm{m}$ & $6: \mathrm{I}_{\mathrm{D}}=221 \mu \mathrm{A}$ & $\mathrm{W}=50.025 \mu \mathrm{m}$ & $\mathrm{I}_{\mathrm{D}}=227.2 \mu \mathrm{A}$ \\
$3: \mathrm{L}=0.42 \mu \mathrm{m}$ & $7: \mathrm{L}_{=}=0.42 \mu \mathrm{m}$ & $\mathrm{L}=0.45 \mu \mathrm{m}$ & $\mathrm{L}=0.45 \mu \mathrm{m}$ \\
$4: \mathrm{V}_{\mathrm{DS}}=0.75 \mathrm{~V}$ & $8: \mathrm{V}_{\mathrm{DS}}=0.75 \mathrm{~V}$ & $\mathrm{~V}_{\mathrm{DS}}=0.51 \mathrm{~V}$ & $\mathrm{~V}_{\mathrm{DS}}=0.99 \mathrm{~V}$ \\
Results: & Results: & & \\
$\mathrm{g}_{\mathrm{m}}=2.0 \mathrm{~mA} / \mathrm{V}$ & $\mathrm{W}=136 \mu \mathrm{m}$ & $\mathrm{g}_{\mathrm{m}}=2.81 \mathrm{~mA} / \mathrm{V}$ & $\mathrm{W}=140 \mu \mathrm{m}$ \\
$\mathrm{I}_{\mathrm{D}}=221 \mu \mathrm{A}$ & $\mathrm{VA}=-10.7 \mathrm{~V}$ & $\mathrm{I}_{\mathrm{D}}=227.2 \mu \mathrm{A}$ & $\mathrm{VA}=-13.44 \mathrm{~V}$ \\
$\mathrm{VA}=-3.64 \mathrm{~V}$ & & $\mathrm{VA}=-3.95 \mathrm{~V}$ & \\
\hline
\end{tabular}

Table 3. Noise: Blue Print X Simulations.

\begin{tabular}{|c|c|c|c|c|c|}
\hline & \multicolumn{3}{|c|}{ Blue Print } & Eq. (11) & Simul. \\
\hline $\begin{array}{c}\mathrm{V}_{\mathrm{DS}} \\
(\mathrm{V})\end{array}$ & $\begin{array}{c}i_{d 1}^{2} \\
\left(\frac{A^{2}}{H z}\right)\end{array}$ & $\begin{array}{c}i_{d 2}^{2} \\
\left(\frac{A^{2}}{H z}\right)\end{array}$ & $\begin{array}{c}\mathrm{VA}_{1} \\
(\mathrm{~V})\end{array}$ & $\left.\begin{array}{c}\sqrt{\mathrm{V}_{\mathrm{N}, \text { in }}{ }^{2}}\left(\frac{n V}{\sqrt{H z}}\right) \\
{ }^{2}\end{array}\right)$ & $\begin{array}{c}\mathrm{V}_{\mathrm{N}, \text { in }}{ }^{2} \\
\left(\frac{n V}{\sqrt{H z}}\right)\end{array}$ \\
\hline 0.9 & $3.68 \mathrm{e}-23$ & $3.70 \mathrm{E}-23$ & -5.77 & 3.232 & 3.193 \\
\hline 1.2 & $3.80 \mathrm{e}-23$ & $3.68 \mathrm{E}-23$ & -6.75 & 3.155 & 3.172 \\
\hline 1.5 & $3.91 \mathrm{e}-23$ & $3.70 \mathrm{E}-23$ & -7.24 & 3.089 & 3.137 \\
\hline 1.8 & $4.03 \mathrm{e}-23$ & $3.73 \mathrm{E}-23$ & -7.46 & 3.028 & 3.115 \\
\hline 2.1 & $4.16 \mathrm{e}-23$ & $3.76 \mathrm{E}-23$ & -7.55 & 2.968 & 3.099 \\
\hline 2.4 & $4.28 \mathrm{e}-23$ & $3.79 \mathrm{E}-23$ & -7.56 & 2.907 & 3.089 \\
\hline
\end{tabular}

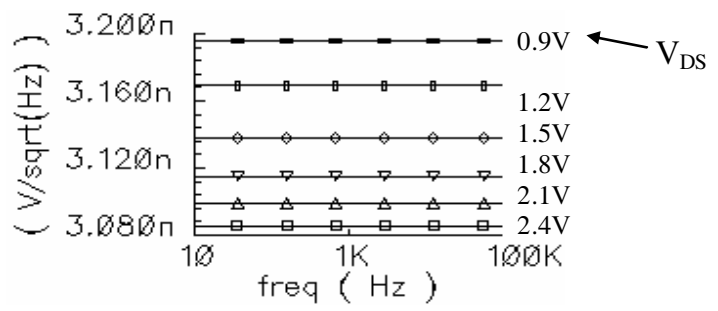

Figure 4. Noise for several values of $V_{D S}$.

$$
V_{N, i n}^{2}=\left(i_{d 1}^{2}+i_{d 2}^{2}\right) \frac{1}{\left(g_{m 1}\left(\frac{V_{D S 1}-V A_{1}}{V_{D S s a t 1}-V A_{1}}\right)\right)^{2}}
$$

Calculations and simulations, again, are very close. Figure 4 shows the graphics of the noise for each $V_{D S}$ presented in Table
3. The thermal noise using the long channel model would be $2.865 \mathrm{nV} / \sqrt{\mathrm{Hz}}$. The design model for the thermal noise with the short-channel effects is more precise than the long channel one.

\section{CONCLUSIONS}

This paper has presented an alternative approach to address short-channel effects for analog design by mixing analytical expression with data points. Short-channel effects were referred to the Early voltage. An engine for extraction of the Early voltage based in a well defined design space and calculation of thermal noise coefficient and thermal noise, as well as a tool for transistor level design were successfully implemented and tested. Theoretical and simulated results were compared and showed very good agreement, therefore, confirming the efficiency of the design method. The results presented here, for transistor level design, can be used as basis to build circuit level design tools.

\section{REFERENCES}

[1] B. Martin, "Automation Comes to Analog", IEEE Spectrum, pp. 70-75, June 2001.

[2] G. G. E. Gielen, R. A. Rutenbar, "Computer-Aided Design of Analog and Mixed-Signal Integrated Circuits", Proceedings of the IEEE, vol. 88, no. 12, December 2000.

[3] Hershenson, M.delM.; Boyd, S.P.; Lee, T.H, "Optimal design of a CMOS op-amp via geometric programming", Computer-Aided Design of Integrated Circuits and Systems, IEEE Trans. on, Volume: 20 Issue: 1, Jan 2001.

[4] A.I.A. Cunha.; Schneider, M.C.; Galup-Montoro, "A MOS transistor model for analog circuit design", IEEE Journal of Solid-state Circuits, vol. 33, No. 10, October 1998.

[5] C. C. enz, F. Krummenacher and E. A. Vittoz, "An analytical MOS transitor model valid in all regions of operation and dedicated to low-voltage and low-current applications", Analog Integrated Circuits and Signal Processing, vol. 8, pp 83-114, July 1995.

[6] A.I.A. Cunha.; Schneider, M.C.; Galup-Montoro, "An explicit physical model for the long-channel MOS transistor including small-signal parameters", Solid-State Electronics, vol. 38, No. 11, November 1995.

[7] F. Silveira, D. Flandre, and P. G. A. Jespers, "A $g_{m} / I_{D}$ Based Methodology for the Design of CMOS Analog Circuits and Its Application to the Synthesis of a Siliconon-insulator Micropower OTA", IEEE Journal of SolidState Circuits, vol. 31, no 9 September 1996.

[8] R. L. Oliveira Pinto, F. Maloberti, "Novel design Methodology for Short-Channel Mosfet Analog Circuits", IWSOC 2003, Calgary-Alberta, Canada, July 2003.

[9] Schneider, M.C.; Galup-Montero, C.; Filho, O.C.G.; Cunha, A.I.A. A single-piece charge-based model for the output conductance of MOS transistors Electronics, Circuits and Systems, 1998 IEEE International Conference on, Volume: 1, 1998.

[10] Shaeffer,D. K, Lee, T. H, "A 1.5 V 1.5 GHz CMOS Low Noise Amplifier," IEEE Journal of Solid State Circuits, Vol. 32, No. 5, pp .745-759, May 1997. 